\title{
Impact of Agricultural Modernization on Crude Birth Rate in Indian Punjab
}

\author{
KARAMAT ALI
}

\begin{abstract}
Pooled cross-section and time-series data of 11 districts in the Indian Punjab have yielded three hypotheses: (1) High infant-mortality rates lead to high fertility rates and high fertility rates cause high infant-mortality rates; (2) Agricultural modernization affects fertility and infant-mortality; and (3) The direction and strength of the effects of agricultural modernization on fertility and infant-mortality depend upon the distribution of the benefits of such modernization.
\end{abstract}

\section{INTRODUCTION}

The economic, social, and political implications of agricultural modernization in less developed countries (LDCs) have been discussed at length in the literature on economic development. The limited objective of this paper is to explore the effects of agricultural modernization on fertility behaviour in Indian Punjab. In the course of this exploration, the discussion will focus on the effects of agricultural change on several socio-economic and demographic characteristics that are known to influence fertility decisions.

In recent years, our understanding of fertility behaviour of households has been enriched by the trend of viewing it within the general framework of choicetheoretic models. ${ }^{1}$ Both the number and the quality of children are treated in such models as matters of choice for the family. These household production models begin with the postulate that households maximize a given utility function. The arguments of this function are non-marketable, home-produced commodities such as good health, nutrition, children, etc. Each one of these basic commodities is produced according to a household production function with inputs of goods and

*The author is an Assistant Professor of Economics at the Bahauddin Zakariya University, Multan (Pakistan). The paper is a part of his Ph. D. thesis submitted to the Vanderbilt University, U.S.A. The author is grateful to Suhas L. Ketkar and members of the Thesis Advisory Committee, Glenn Firebaugh, Ivar Berg, Anthony Oberschall, and David Dunlop, for their guidance. The author also thanks Professor Gian S. Sahota and Chandera K. Sahota for making available to him the Punjab (India) data set. Any errors or omissions are, however, the responsibility of the author alone.

${ }^{1}$ The papers by Becker [4] and Lancaster [16] laid the foundation of these recent economic approaches to fertility. Other contributions of note in this area, from both theoretical and empirical perspectives, are those of Gary Becker [3], Schultz[18] and Bean-Porath [2]. 
services purchased in the market and the time expended on home production by various members of the household. Consequently, two constraints on utility maximization become relevant: (a) the household's full income, and (b) the time available with the household members. The extent of time available for producing basic commodities within a household depends upon a couple's decision regarding the number of hours of work to be performed outside the home which, in turn, is governed by the reward for labour and the perceived marginal productivity in producing basic commodities, such as children. Subject to the full-income and time constraints, a household is postulated to maximize its utility function. The demand for children - both the number of children and their quality - is then derived from this constrained utility-maximizing behaviour.

Many problems are encountered in making the above theoretical formulation empirically operational. The fundamental problem is that the theory of fertility behaviour is stated in static terms whereas the facts we observe are the results of market and non-market variables and decisions taken in response to them over long periods of time. (For details, see Gardner [9]). In addition, the household production model, as it now stands, is not well suited to treat the particular class of circumstances that constrain the behaviour of households in low-income countries. As T.W. Schultz [23] has put it, "These are countries in which illiteracy abounds human time is cheap, and the income opportunities that women have outside the home are not mainly jobs in the labor market. Furthermore, infant-mortality is high, life-expectancy at birth is low, debilitation during the adult years is substantial for reasons of inadequate nutrition and endemic diseases, and the availability of modern contraceptive techniques, including information about them, is, in general, wanting. These classes of circumstances are not as yet at home in the household model."

In outlining a theory of fertility suitable to a study of the family formation behaviour in predominantly agricultural societies, we shall endeavour to address ourselves to at least some of the special circumstances that are believed to constrain the behaviour of households in poor countries.

In developing countries, which are predominantly agricultural, it is a plausible postulate that demographic variables have been affected by the changes in agricultural sector (i.e. modernization of agriculture) which occurred during the last two decades and which are taking place at present. The impact of agricultural modernization on fertility through variables, such as infant mortality rate, per capita income, distribution of income and education, can be significant.

The paper is planned as follows. In Section II, issues relating to household production model are discussed which concludes with an econometric specification of the model that embodies birth rate and infant-mortality rate as endogenous variables. In Section III, the model estimated in the study is specified and there is a discussion on linkages between agricultural modernization and each one of the exogenous variables in the birth and infant-mortality rate equations. The model is estimated for the pooled cross-sectional and time-series observations for 11 districts of the Indian Punjab for the years 1961-71. The two-stage least-squares (TSLS) estimates of the model are presented in Section IV. The concluding section, Section V briefly comments on the main implications of the exercise.

\section{THEORETICAL CONSIDERATIONS: THE HOUSEHOLD PRODUCTION MODEL}

As already stated, in most household production models of fertility, the rate of infant-mortality is usually introduced as an exogenous parameter which affects the costs and benefits of children. But, quite clearly, the quality and quantity of inputs used for the rearing of children would influence the likelihood of child survival. The nutrient intake of the pregnant mother, the duration of nursing, the character of the weaning process, the exposure to environmental risks, the access to and the use of health facilities, and the quantity and quality of nutritional intake after weaning are the factors that influence infant mortality rates and are at least partially within the control of the family. The health status of any child would also depend upon the parents' decision regarding the number of children to bear and the spacing between them. The larger the family size, the smaller are likely to be the resources available to any particular child, thereby reducing the child's probability of survival.

In reformulating the household production model in which the infant mortality rate is endogenous, the parents are assumed to maximize a utility function of the following type:

$$
\mathrm{U}=\mathrm{U}(\mathrm{pn}, \mathrm{q}, \mathrm{s})
$$

where $\mathrm{n}$ is the number of children, $\mathrm{p}$ is the probability of child survival, $\mathrm{q}$ is the average child quality, and $s$ is the family's standard of living. The average child quality, q, is determined by the available resources per living child, i.e.

$$
\mathrm{q}=\mathrm{q}(\mathrm{tc} / \mathrm{pn}, \mathrm{Xc} / \mathrm{pn} ; \mathrm{k})
$$

where tc and $\mathrm{Xc}$ are the total time and resource inputs used for child rearing, and $\mathrm{k}$ is the quality of parental time input.

Since $\mathrm{p}$ is no longer exogenous to the family,

$$
\mathrm{p}=\mathrm{p}(\mathrm{q}, \mathrm{n} ; \mathrm{E})
$$

where $\mathrm{E}$ is the quality of milieu in which the infant grows.

${ }^{2}$ This section draws heavily upon Heller's work [14] 
In addition, $\mathrm{s}$ is a function of parental consumption, $\mathrm{xs}$, and leisure, ts :

$$
\mathrm{s}=\mathrm{s}(\mathrm{xs}, \mathrm{ts})
$$$$
\cdots
$$

The utility function in Equation (1) is maximised, subject to constraints (2), (3), and (4) and in addition to the constraints of the availability of a family's full income and total time. Thus,

$$
\mathrm{PsXs}+\mathrm{PcXc}=\mathrm{wL}+\mathrm{Ao} \quad \ldots
$$

and

$$
\mathrm{T}=\mathrm{L}=\mathrm{tc}+\mathrm{ts}
$$

where $\mathrm{Ps}$ and $\mathrm{Pc}$ are the prices of $\mathrm{Xs}$ and $\mathrm{Xc}$, respectively, $\mathrm{w}$ is the wage rate, $\mathrm{L}$ is the total market time input of the family, and Ao is the household's non-earned income from assets.

The demand function for children that can be derived by maximizing Equation (1), subject to constraints (2) through (6), would be a function of the price and wage parameters, the level of non-earned income, the quality of parental time input, and, $p$, the endogenous probability of child survival. In addition, from the point of view of econometric specification, one can now specify a structural equation for $\mathrm{p}$ as a function of $\mathrm{n}, \mathrm{q}$, and other exogenous parameters. In short, the level of fertility and infant mortality can be treated as structurally interdependent.

\section{MODEL SPECIFICATION}

\section{The Model}

In contrast to the usual specification of the model in which infant mortality is generally treated as an exogenous determinant of the number of births in the family, it is postulated in this analysis that the family has some influence over the survival of its children. ${ }^{3}$ An important implication of this assumption is a change in the

${ }^{3}$ This is a necessary consequence of the Grossman's 1972 - type models [10] on the demand for health. Grossman has argued that health capital of parents should be treated as endogenous to the family-decision process. If one accepts this, then the probability of child survival must also be treated as endogenous to the family-formation process. Heller [14] has made this point forcefully. Heller talks about both biological and behavioural linkages. Although there is point forcefully. Heller talks about both biological and behavioural linkages. Although there is
evidence that biological influences are stronger at the early stages of the demographic transition, there is some influence of the family over the survival of its children. econometric specification of the model whereby birth rate and infant-mortality rate are treated as endogenous variables. The model is specified as follows:

$$
\begin{array}{lll}
\mathrm{IMR}=\mathrm{F} & {[(\mathrm{BR}) ; \mathrm{L}, \mathrm{E}, \mathrm{Q}, \mathrm{G}]} \\
\mathrm{BR}=\mathrm{G} & {[(\mathrm{IMR}) ; \mathrm{W}, \mathrm{Y}]}
\end{array}
$$

where

$\mathrm{BR}=$ Rural Crude Birth Rate;

IMR = Rural Infant Mortality Rate;

$\mathrm{W}=$ Wage Rate in Rupees at the 1960-61 prices;

$\mathrm{Y}=$ Per capita gross agricultural income (i.e. value of 13 major crops; at the 1960-61 prices, in rupees divided by rural population);

$\mathrm{L}=$ Initial overall educational index: literate and educated persons as percent of total population;

$\mathrm{E}=$ Percent of villages with electricity;

$\mathrm{Q}=$ Quantity of wheat produced per capita; and

$\mathrm{G}=$ Gini-coefficient of land holding.

Figure 1 depicts the model and indicates the expected sign of each relationship.

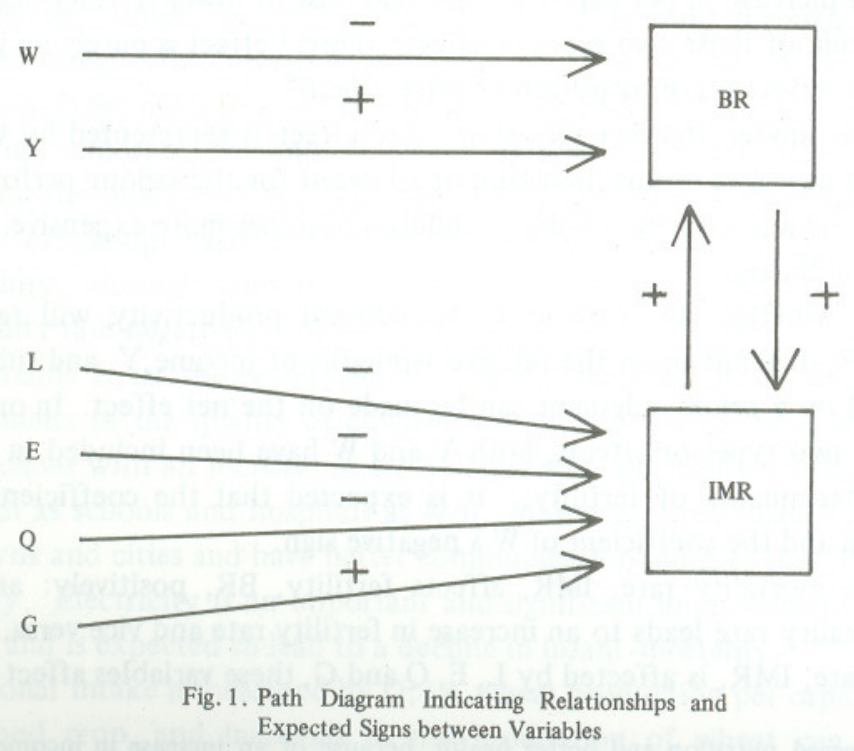


We will now look at each of these expected relationships, beginning with the determinants of fertility.

\section{The Determinants of Fertility}

In the equation for birth rate, infant-mortality rate is an endogenous variable. The exogenous variables are wage rate $\mathrm{W}$, and per capita income $\mathrm{Y}$.

$\mathrm{W}$ is the prevailing district wage rate for weeding activity, which is assumed to be closer to the average yearly wage than the wage rates for ploughing, harvesting, sowing, and other agricultural operations. Moreover, as weeding activity is dominated by women, it is expected that $\mathrm{W}$ measures the value of female time which is of interest to us in this study. A priori, we expect W to be negatively related to BR.

$\mathrm{Y}$ is the per capita income of rural population from 13 major crops at the 1960-61 prices. An increase in per capita income leads to higher fertility when all other variables are controlled, but a negative relationship is expected when other variables are not controlled. The effect of income on fertility can be divided into two components: direct effect and indirect effect. The direct effect of an increase in per capita income is increased fertility because one can afford to rear more children. On the other hand, as income increases, there are also increases in other variables such as education, health facilities, nutritional status, and consumption of goods and services, which lead to a decline in fertility. Consequently, since the direct effect of an increase in income is increased fertility and the indirect effect is decreased fertility, an increase in per capita income will raise or lower fertility depending upon the magnitude of these two types of effects. Direct effect is purely an income effect and indirect effect is a substitution or price effect. ${ }^{4}$

In this model, indirect effect or price effect is represented by wage rate, W. An increase in wages means increasing the reward for the labour performed outside the home. As a result, the rearing of children becomes more expensive, and fertility, $\mathrm{BR}$, tends to decline.

Thus, whether an increase in agricultural productivity will raise or lower fertility, BR, depends upon the relative strengths of income, Y, and substitution, W, effects, and no a priori judgment can be made on the net effect. In order to distinguish these two types of effects, both $\mathrm{Y}$ and $\mathrm{W}$ have been included in the equation for the determinants of fertility. It is expected that the coefficient of $\mathrm{Y}$ has a positive sign and the coefficient of $\mathrm{W}$ a negative sign.

Infant-mortality rate, IMR, affects fertility, BR, positively: an increase in infant-mortality rate leads to an increase in fertility rate and vice versa. Since infant mortality rate, IMR, is affected by $\mathrm{L}, \mathrm{E}, \mathrm{Q}$ and $\mathrm{G}$, these variables affect fertility, BR,

${ }^{4}$ Increased nutrition and better health, because of an increase in income, may result in increased or decreased fertility through a complex biological and sociological mechanism - not necessarily the economists' pure income effect and substitution or price effect. See Berg [5], Heer [13], Austin and Levinson [1] and Brown [7]. through IMR. Thus, the total effect of IMR on fertility can be divided into two components; viz. the direct effect of IMR on fertility and the indirect effects of L, E, $\mathrm{Q}$ and $\mathrm{G}$ on fertility through IMR. High child-mortality introduces a degree of uncertainty into the family-formation process. What is the likely effect of this uncertainty on the number of children ever born in a family? To answer this question, one has to consider two offsetting effects. One effect of high child-mortality is to raise the cost of rearing a child to maturity, which leads to a decline in fertility. The other effect of change in IMR on fertility is directly through the lactation effect and indirectly through the desired number of surviving children. The latter includes lag; see Schultz [21]. This effect is stronger in agricultural societies because there is no old -age security in such societies.

\section{The Determinants of Infant-Mortality}

In the infant-mortality rate equation, birth rate, $\mathrm{BR}$, is the endogenous variable, and literacy index, L, percent of villages with electricity, E, per capita wheat production, Q, and Gini-coefficient of land holding, G, are the exogenous variables.

The variable $\mathrm{L}$ is used to assess the influence of changes in the quality of parental time-input in the rearing of children. It also indicates changes in the attitudes of parents toward health, sanitation and nutrition for themselves and for their children. The IMR is expected to be negatively influenced by L. Educated parents are likely to provide better child care, thereby reducing infant mortality and indirectly affecting fertility negatively. The educational level of parents in predominantly agricultural societies indirectly affects fertility through infant-mortality, and the direct effect may not be significant. The direct effects of education on fertility, which are more relevant in developed countries, are the value of time and cost in rearing children; the importance of determined investment in children's education; and the quality of children. Education level, therefore, is treated in this model as an exogenous variable in the equation for infant-mortality. Education affects fertility through infant-mortality, and is expected to affect the infant-mortality rate negatively.

The variable E, i.e. the percentage of villages with electricity, is used as a proxy for improvements in the quality of environment, and, therefore, it is hypothesized that IMR declines with an increase in E. Villages with electricity usually have other facilities, such as schools and hospitals as well. Moreover, such villages are generally closer to towns and cities and have better communication linkages than villages without electricity. Electricity is an important and significant improvement in the livin environment and is expected to lead to a decline in infant-mortality.

Nutritional intake is measured by Q, i.e. wheat production per capita. Wheat the major food crop, and increases in the production of wheat can be a good indicator of improvements in nutrition since increased wheat production results in 
greater availability of food and, hence, in greater likelihood of meeting nutritional standards. Wheat is one of the two crops (along with rice) whose production increased dramatically in these districts during the 1961-71 "green revolution" as a result of improvements in the agricultural sector. It is postulated that $\mathrm{Q}$ influences IMR inversely.

The Gini-coefficient of land holding, G, which measures the degree of inequality in each district, is expected to affect the infant-mortality rate, IMR, positively. The relationships between income distribution, infant-mortality and fertility have been emphasized in recent economic literature, and empirical evidence suggests that income inequality, infant-mortality and fertility are positively related. The distribution of income affects fertility through changes in infant-mortality. A skewed distribution of income means that a small number of people enjoy good health, nutrition, sanitation, and educational facilities, while a large number of people live at the subsistence level without these facilities. Infant-mortality is high for the latter group of people, and if infant-mortality is high, fertility is high, too. A highly skewed pattern of land ownership leads to unequal distribution of income in rural areas and is responsible for the high infant-mortality rate. Therefore, the Gini-coefficient of land holding is expected to be positively related to infantmortality.

Birth rate, which is an endogenous variable in the infant-mortality rate equation, and is determined by wage rate and per capita income, is positively related to the infant-mortality rate. A high birth rate means less food and time for child care at the family level, and more pressure on the meagre resources available for health and educational facilities. This results in high infant-mortality. Wage rate and per capita income indirectly affect infant-mortality through fertility. High wage rates lead to lower fertility, and that, in turn, affects the infant-mortality rate negatively.

The most important relationship hypothesized in this study is that a high infant-mortality rate leads to a high birth rate, and, conversely, that a high birth rate leads to a high infant-mortality rate. There is a vicious circle of high infantmortality and fertility rates.

\section{The Role of Agricultural Modernity}

This part discusses how agricultural modernization has affected fertility and infant -mortality in predominantly agricultural countries, which is the main theme of the study.

Agricultural modernization leads to an increase in productivity and income, $\mathrm{Y}$, which positively affects fertility, BR. Agricultural output per hectare, output per agricultural labourer and income per capita increase with the increasing use of new techniques of production, seeds, fertilizer and improved irrigation facilities. A rise in agricultural productivity not only increases income, but also raises the reward for the labour performed outside the home, i.e. wages, W. As the productivity of labour increases, the wage rate also increases. Wage increases, which are the result of agricultural modernization, make the rearing of children more expensive, which in turn causes fertility to decline.

The production of wheat, Q (the major food crop in these areas), and rice increased dramatically during the 1961-71 period as a result of an increased use of fertilizers, new seed varieties an improved irrigation facilities in the districts of the Indian Punjab. Agricultural modernization is expected to increase the supply of wheat and availability of food, thereby reducing malnutrition. This leads to a decline in infant-mortality, which leads to lower fertility.

Whether agricultural modernization is likely to improve or worsen the distribution of income, which affects infant-mortality, is a hotly debated issue. The agrarian structure of the country, the type of technology being promoted, and the extent of diffusion of this technology are all important in determining the impact of agricultural modernization on the distribution of income. The Gini-coefficient of land holding, G, which is an indicator of the pattern of land ownership in a country, is an important factor in determining the effects of agricultural modernization on the distribution of income, and, indirectly, on infant-mortality. A highly skewed pattern of land ownership is conducive to mechanization, which displaces labour and widens the income inequality in rural areas. Consequently, there will be little decline in infant-mortality and, indirectly, in fertility. If land is equally distributed, the benefits of agricultural modernization are likely to be evenly spread, bringing about a decline in infant-mortality and, through that, in fertility.

\section{EMPIRICAL RESULTS}

The present study has utilized data collected and reported by Sahota and Sahota [17].

The model is estimated for pooled cross-sectional and time-series observations for the 11 districts of the Indian Punjab for the years 1961-71.5 Pooling of crosssectional and time-series data increases the number of observations, and thereby increases the accuracy of the estimates. Moreover, such a data base increases the flexibility of the analysis; in particular, one can do separate cross-sectional and timeseries analysis. Divergence between cross-sectional and time-series relationships is often helpful in identifying spurious relationships, see Firebaugh [8] .

On the other hand, convergence in results suggests that the underlying crosssectional and time-series structures are similar, thereby (i) giving one more confidence in the specification of the model; and (ii) providing a rationale for

${ }^{5}$ Pooling of cross-sectional and time-series data increases the number of observations, but does not result in independent observations. This does not lead to any bias in the results but $\mathrm{t}$-values associated with the coefficients are over-estimated. 
pooling the two types of data. In this case, the cross-sectional and time-series relationships converge except for literacy. Table 1 presents, for pooled, timeseries and cross-district data, the zero-order correlations between birth rates, BR, and the variables which affect BR directly, including wages, $\mathrm{W}$, income, $\mathrm{Y}$, and infant mortality rates, IMR. The zero-order correlations between BR and $W$ are, as expected, negative in all cases. Similarly, BR and $\mathrm{Y}$ are negatively related: only two zero-order correlations are positive in value, and they are insignificant. Zero-order correlations indicate that IMR and BR are positively related in all cases.

Table 2 presents the zero-order correlation between IMR and other exogenous variables in equation. Again, only variables which affect IMR directly have been included. As expected, all zero-order correlations between IMR and per capita wheat production, Q, are negative. Zero-order correlations between Gini-coefficient of land holding, G, and IMR could not be calculated for time-series data because Gini-coefficients are assumed to be constant for the period 1961-71. However, all cross-district zero-order correlations between IMR and G are positive, as expected. Zero-order correlations between IMR and literacy, L, are negative for time-series data, but positive for cross-district data. This suggests that infant-mortality rates were initially higher in the districts with more literacy, but as literacy increased, infant-mortality rates declined in all districts between 1961 and 1971. A more detailed analysis of this phenomenon will be made in the following discussion of the results of the regression equations. Most of the zero-order correlations between IMR and the percent of villages with electricity, E, are negative, as expected, and some of those that are positive are not significant.

These zero-order correlation coefficients indicate the slopes of different variables' relationships and justify that in this case cross-district, time-series and pooled regression structures are nearly equivalent.

The two-stage least-squares (TSLS) estimates of the model and the zeroorder correlation matrix are presented in Tables 3,4 , and 5 . In the birth-rate equation (Table 3), infant-mortality rates enter as an instrument derived in the first stage of the TSLS procedure, and the results of the equation suggest a positive impact of infant-mortality rate on fertility. The coefficient of the IMR is positive and the $t$-value is significant at $\alpha=.01$. This is consistent with the proposition that high infant-mortality causes families to desire a larger family. Thus, the results lend support to the hypothesized positive relationship between fertility and infant-mortality, which has also been confirmed on the basis of statistical evidence for different countries at different periods of time, such as Bangladesh (1951-61), Puerto Rico (1950-60), Taiwan (1964-69), Chile (1960) and the Philippines (1968). For details, please see Schultz [19] .

As shown in Table 3, the other important determinant of fertility is the wage rate, $W$. As expected, the wage rate variable is negatively related to fertility, and the coefficient is statistically significant at $\alpha=.05$. This is the wage rate for weeding,
Table 1

Zero-Order Correlations Between Birth Rates and Other Variables Using Time-Series, Cross-Sectional and Pooled Data for the Districts of Punjab,1961-71

Correlations Between Birth Rate and

\begin{tabular}{|c|c|c|c|}
\hline & & & \\
\hline Type of Data & Wage Rate (W) & Income (Y) & $\begin{array}{c}\text { Infant Mortality } \\
\text { Rate (IMR) }\end{array}$ \\
\hline Cross-Sectional and & & & \\
\hline Time-Series Pooled & -.5438 & -.3979 & 6133 \\
\hline Time-Series & & & \\
\hline Amritsar & -.8028 & -.6377 & .6935 \\
\hline Bhatinda & -.3949 & -.4634 & .5836 \\
\hline Ferozepur & -.9246 & -.8052 & .1678 \\
\hline Gurdaspur & -.8323 & -.7801 & .7880 \\
\hline Hoshiarpur & -.6986 & -.0119 & 6194 \\
\hline Jullundur & -.5441 & -.6897 & .7042 \\
\hline Kapurthala & -.2768 & -.1267 & .5849 \\
\hline Ludhiana & -.8608 & -.8672 & .4275 \\
\hline Patiala & -.1739 & -.2437 & .4106 \\
\hline Ropar & -.2992 & .0278 & .3197 \\
\hline Sangrur & -.0752 & -.0937 & .5559 \\
\hline Cross-District & & & \\
\hline 1961 & -.3357 & -.3364 & .6366 \\
\hline 1962 & -.8076 & -.6011 & .6249 \\
\hline 1963 & -.4534 & -.1854 & .3984 \\
\hline 1964 & -.3542 & -.0993 & .6692 \\
\hline 1965 & -.2570 & -.1460 & .4798 \\
\hline 1966 & -.4458 & -.1844 & .5775 \\
\hline 1967 & -.7163 & .0411 & .1007 \\
\hline 1968 & -.7443 & -.2452 & .7470 \\
\hline 1969 & -.7898 & -.5688 & .5432 \\
\hline 1970 & -.6794 & -.6073 & .7783 \\
\hline 1971 & -.6221 & -.5162 & .8222 \\
\hline
\end{tabular}


Zero-Order Correlation Co-Lfficients of IMR with Other

Variables for Time-Series, Cross-Sectional and Pooled Data for the Districts of Punjab, 1961-1971

Correlations Between Infant -Mortality Rate and

Per Capita Literacy Index Percent Villages Gini-Co-

Type of Data

Per Capita Literacy Index Percent Villages

(L) With Electricity

(E)

efficient of

tion $(\mathrm{Q})$

ings (G)

Cross-Sectional and

Time-Series Pooled

Time-Series

$\begin{array}{llll}\text { Amritsar } & -.8326 & -.8271 & -.6853 \\ \text { Bhatinda } & -.5050 & -.4896 & -.5044 \\ \text { Ferozepur } & -.1789 & -.0198 & -.0113 \\ \text { Gurdaspur } & -.8259 & -.9223 & -.8618 \\ \text { Hoshiarpur } & -.3397 & -.7166 & -.5792 \\ \text { Jullundur } & -.8473 & -.8350 & -.7942 \\ \text { Kapurthala } & -.5547 & -.7091 & -.5274 \\ \text { Ludhiana } & -.6028 & -.6448 & -.6738 \\ \text { Patiala } & -.6241 & -.7875 & -.7183 \\ \text { Ropar } & -.0295 & -.3919 & -.0244 \\ \text { Sangrur } & -.5924 & -.2229 & -.3037\end{array}$

Cross-District

\begin{tabular}{lrrrl}
1961 & -.7355 & .6461 & .1110 & .0874 \\
1962 & -.6724 & .6516 & .1284 & .4687 \\
1963 & -.7454 & .3759 & -.2023 & .4866 \\
1964 & -.5085 & .5576 & -.0208 & .5844 \\
1965 & -.4566 & .5167 & -.0901 & .4482 \\
1966 & -.2117 & .4787 & -.1502 & .6009 \\
1967 & -.0078 & .3283 & .1987 & .5796 \\
1968 & -.1452 & .6839 & .0923 & .4889 \\
1969 & -.8497 & .7024 & -.0558 & .1331 \\
1970 & -.1204 & .3392 & -.1850 & .2379 \\
1971 & -.1911 & .4198 & -.3916 & .6030 \\
\hline
\end{tabular}

Gini-Coefficient

is constant over

period of time

$-$

$-$

$-$

$-$
Determinants of Birth Rate in Eleven Districts of the Indian Punjab, 1961-1971 (Pooled) $)^{\mathrm{a}, \mathrm{b}}$

$\mathrm{BR}=\mathrm{G} \quad[(\mathrm{IMR}) ; \mathrm{W}, \mathrm{Y}]$

\begin{tabular}{lc}
\hline Independent Variables & Regression Coefficient \\
\hline Endogenous & $0.127^{* *}$ \\
$\quad$ Infant-Mortality Rate (IMR) & $(3.421)$ \\
& \\
Exogenous & $-0.764^{*}$ \\
Wage Rate (W) & $(2.187)$ \\
& \\
Per Capita Income (Y) & 0.001 \\
\end{tabular}

No. of observations $=121$

$\mathrm{R}^{2}=.42$

*Shows significance at the 5 -percent level.

**Shows significance at the 10 -percent level.

$\mathrm{t}$ - ratios are given in parenthesis.

${ }^{a}$ Income statistics for the district of Ropar were available only from 1964 onward. It was assumed that the income data were the same for 1961-1964. A regression equation was estimated excluding District Ropar and results were not significantly different.

${ }^{\mathrm{b}} \mathrm{A}$ regression equation was also estimated including family planning as an exogenous variable. $\mathrm{R}^{2}$ for that equation was .44 , which indicates that family planning did not explain a signif cant amount of the variance in fertility. Moreover, family planning was positively related to birth rates because family planning was selectively pursued by government policies in districts with high fertility rates.

an activity in which women's participation is high, and, therefore, is ideal for capturing the substitution effect of increases in the value of female time on the number of births. The coefficient for per capita income is positive, but not statistically significant. The effect of income on fertility is positive, but the price effect or substitution effect (as indicated by wages) is negative.

The TSLS results on the determinants of infant-mortality are presented in Table 4. In the reported equation, birth rate, BR, enters as an instrument derived in the first stage of the TSLS procedure. 
Table 4

Determinants of Infant-Mortality Rate in Eleven Districts of the Indian Punjab, 1961-1971 (Pooled) ${ }^{\mathrm{a}}$

$\mathrm{IMR}=\mathrm{F}(\mathrm{BR}) ; \mathrm{L}, \mathrm{G}, \mathrm{E}, \mathrm{Q}$
Regression Coefficient

( $\mathrm{t}$-value)
Independent Variables

\section{Endogenous}

Birth Rate (BR)

2.811

$(3.693)^{* *}$

\section{Exogenous}

$\begin{array}{cc}\text { Literacy Index (L) } & 0.623 \\ (2.137) *\end{array}$

Gini-Coefficient of Land Holdings (G)

44.278

$(1.664)^{*}$

Percentage of Villages with Electricity (E)

$-0.323$

$(3.563)^{* * *}$

Per Capita Wheat Production (Q)

$-0.186$

$(1.968)^{*}$
No. of observations $=121$

$\mathrm{R}^{2}=.52$

Notes: *shows significance at the 5 -percent level. ** shows significance at the 1 -percent level. $t$-statistics reported in the parenthesis.

${ }^{\mathrm{a}}$ The statistics for the percentage of villages with electricity and per capita wheat production for District Ropar were available only from 1964 onward. It was assumed that these statistics were constant during 1961-64. A regression equation was estimated excluding District Ropar and the results were similar.

The results suggest a positive impact of fertility, BR, on infant mortality. The coefficient of the BR variable has a positive value of 2.8 , and the $t$-value associated with the coefficient is significant at $\alpha=.01$. This supports the postulated positive impact of birth rates on infant-mortality.

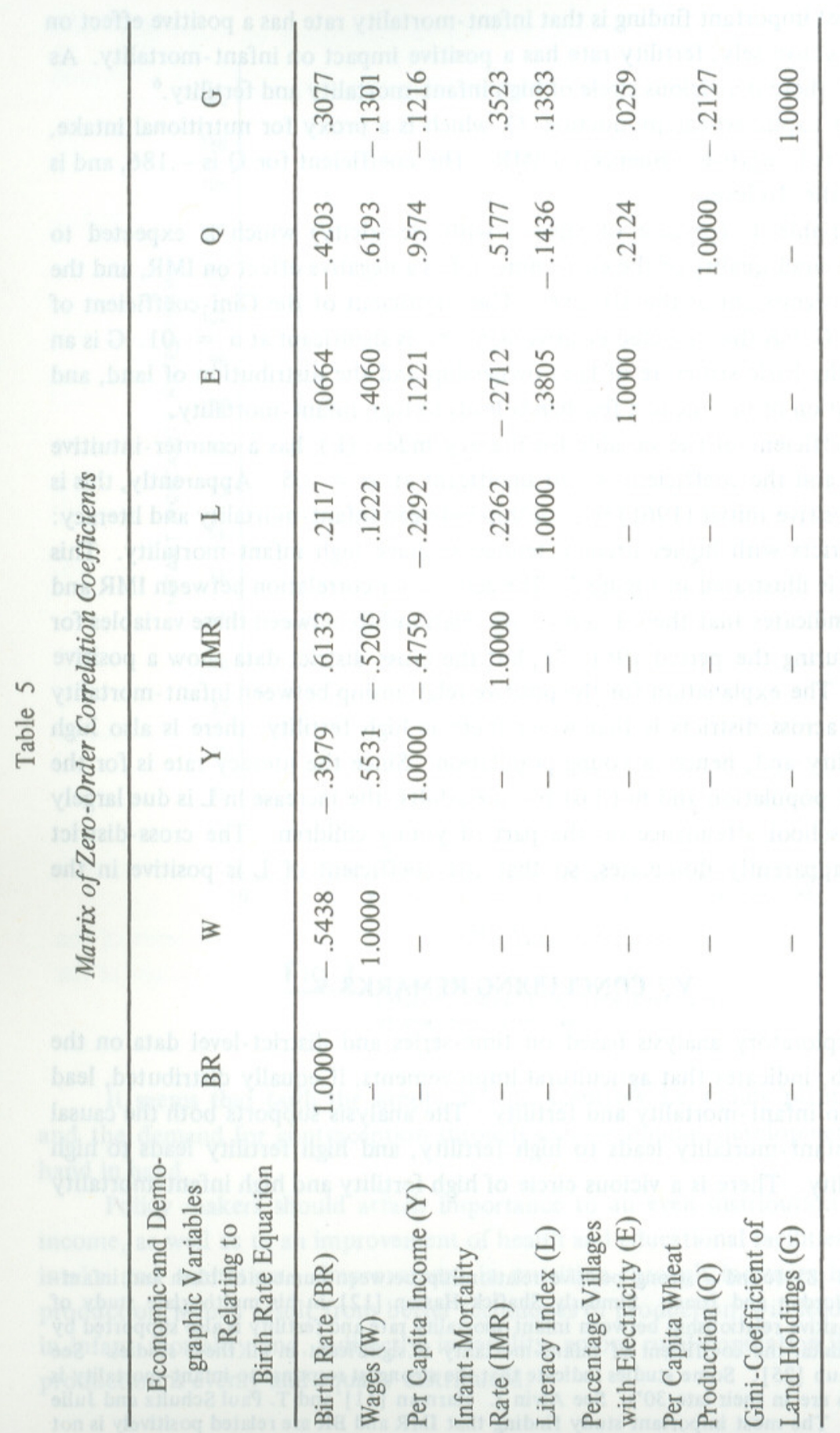


The most important finding is that infant-mortality rate has a positive effect on fertility and, conversely, fertility rate has a positive impact on infant-mortality. As hypothesized, there is a vicious circle of high infant-mortality and fertility. ${ }^{6}$

The per capita wheat production, Q, which is a proxy for nutritional intake, has the expected negative influence on IMR. The coefficient for Q is -.186, and is significant at the .10 level.

The variable E (percent of villages with electricity) which is expected to capture the overall quality of the environment, has a negative effect on IMR, and the coefficient is significant at the .01 level. The coefficient of the Gini-coefficient of land holding, $\mathrm{G}$, has the expected positive sign, and is significant at $\alpha=.01 . \mathrm{G}$ is an indicator of the basic structure of land ownership and the distribution of land, and the concentration of income in a few hands leads to high infant-mortality.

The coefficient of the variable for literacy index, (L), has a counter-intuitive positive sign, and the coefficient is also significant at $\alpha=.05$. Apparently, this is due to the positive initial (1961) relationship between infant-mortality and literacy: in 1961, districts with higher literacy tended to have high infant-mortality. This phenomenon is illustrated in Figure 2. The zero-order correlation between IMR and $\mathrm{L}$ (Table 2) indicates that there is a negative relationship between these variables for all districts during the period 1961-71, but the cross-district data show a positive relationship. The explanation for the positive relationship between infant-mortality and literacy across districts is that when there is high fertility, there is also high infant-mortality and, hence, a young population. Since the literacy rate is for the entire district population and not just for the adults, the increase in $\mathrm{L}$ is due largely to increased school attendance on the part of young children. The cross-district relationship apparently dominates, so that the coefficient of $\mathrm{L}$ is positive in the pooled data.

\section{CONCLUDING REMARKS}

This exploratory analysis based on time-series and district-level data on the Indian Punjab, indicates that agricultural improvements, if equally distributed, lead to a decline in infant-mortality and fertility. The analysis supports both the causal links: high infant-mortality leads to high fertility, and high fertility leads to high infant-mortality. There is a vicious circle of high fertility and high infant-mortality rates.

${ }^{6}$ Schultz [8] found a strong positive relationship between number of birth and infantmortality for Jordan and Israel. Similarly Shafick Hassan [12] in his multivarfate study of Egypt. The positive relationship between infant-mortality rate and fertility is also supported by cross country data the coefficient of infant-mortality is significant in all these studies. See coss studies indicate that the strongest response to infant-mortality is Robert Weintraub $[25]$. Some studies indicate that the strongest response to infant-mortality is

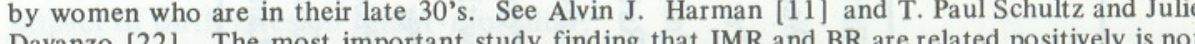
st important study finding that IMR and BR are related positively is no

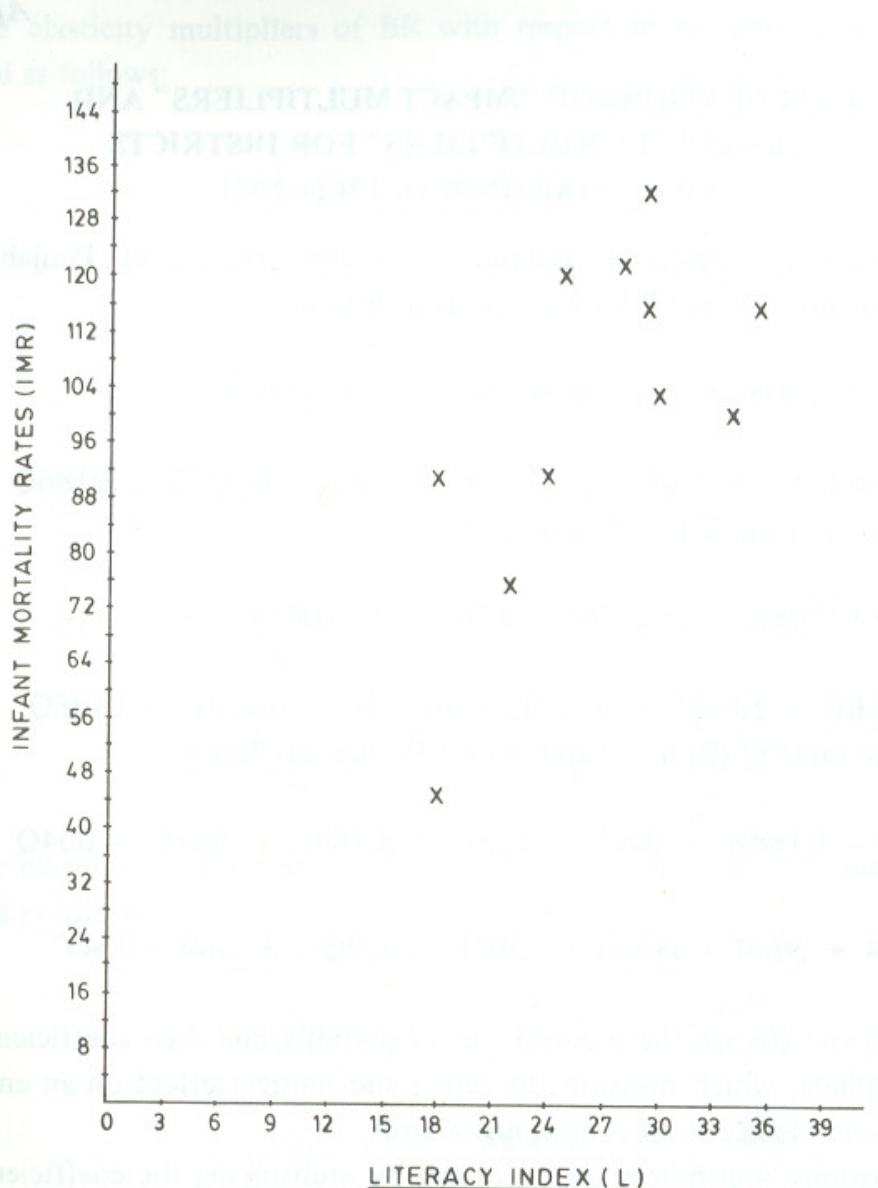

Fig.2 Intant Mortality Rates (IMR) and Literacy Index (L) For the Districts

It seems that both the supply of contraceptives, i.e. family planning services, and the demand for contraception through socio-economic development should go hand in hand.

Policy makers should attach importance to an even distribution of land and income, as well as to an improvement of health and educational facilities, nutritiona intake and sanitation. Improvement in nutrition through increases in agicultural production, which result from better techniques of production, will lead to a decline in infant-mortality and, indirectly, in fertility, among rural population if agricultura production is evenly and equally distributed. 
The elasticity multipliers of BR with respect to exogenous variables can be

\section{CALCULATIONS OF “IMPACT MULTIPLIERS” AND "ELASTICITY MULTIPLIERS” FOR DISTRICTS OF PUNJAB (INDIA): 1961-1971}

The two-stage regression equations for the districts of Punjab (India), 1961-71, as mentioned in Tables 3 and 4 are as follows:

$\mathrm{BR}=22.2738+0.127 \mathrm{IMR}-0.764 \mathrm{~W}+0.001 \mathrm{Y}$

$\mathrm{IMR}=-20.685+2.811 \mathrm{BR}+0.623 \mathrm{~L}+44.278 \mathrm{G}-0.323 \mathrm{E}-.0186 \mathrm{Q} \ldots$ (2)

From equations (1) and (2), one can derive:

$$
\mathrm{BR}-0.127 \mathrm{IMR}=22.2738-0.764 \mathrm{~W}+0.001 \mathrm{Y}
$$

IMR $-2.811 \mathrm{BR}=20.685+0.623 \mathrm{~L}+44.278 \mathrm{G}-0.323 \mathrm{E}-.0186 \mathrm{Q}$

By putting the value of (2) in (3) and (1) in (4), one can derive :

$\mathrm{BR}=30.55-1.188 \mathrm{~W}-.002 \mathrm{Y}+123 \mathrm{~L}+8.744 \mathrm{G}-.064 \mathrm{E}-.004 \mathrm{Q}$

$\mathrm{IMR}=65.194+.969 \mathrm{~L}+68.851 \mathrm{G}-502 \mathrm{E}-.029 \mathrm{Q}-3.338 \mathrm{~W}+004 \mathrm{Y}$

Equations (5) and (6) are the reduced-form equations, and their coefficients are the impact multipliers, which measure the direct and indirect effect on an endogenous variable of a unit change in an exogenous variable.

The elasticity multipliers are calculated by multiplying the coefficients of the reduced form equations (impact multipliers) by the ratio of the average values of the two variables involved. The mean values of the variables are as below:

$$
\begin{aligned}
& (\mathrm{BR}, \mathrm{W})=-1.226 \times \frac{4.126}{29.94}=-.17 \\
& (\mathrm{BR}, \mathrm{Y})=.002 \times \frac{232.537}{29.94}=.02 \\
& (\mathrm{BR}, \mathrm{L})=.127 \times \frac{30.341}{29.94}=.13 \\
& (\mathrm{BR}, \mathrm{G})=9.024 \times \frac{0.398}{29.94}=.12 \\
& (\mathrm{BR}, \mathrm{E})=.006 \times \frac{32.517}{29.94}=-.07 \\
& (\mathrm{BR}, \mathrm{Q})=.004 \times \frac{336.198}{29.94}=-.05
\end{aligned}
$$

The elasticity multipliers of IMR with respect to exogenous variables can be calculated as follows:

$$
\begin{aligned}
& (\text { IMR, L })=\quad .969 \times \frac{30.341}{83.253}=.35 \\
& \left(\text { IMR, G }=\quad 68.851 \times \frac{.398}{83.253}=.33\right. \\
& (\text { IMR, E })=-.502 \times \frac{32.517}{83.253}=-.19 \\
& \left(\text { IMR, Q ) }=-0.29 \times \frac{336.198}{83.253}=-.12\right. \\
& \left(\text { IMR, W }=-3.338 \times \frac{4.126}{83.253}=-.16\right. \\
& \left(\text { IMR, Y) }=\quad .004 \times \frac{332.537}{83.253}=.01\right.
\end{aligned}
$$




\section{REFERENCES}

1. Austin, James, and James Levinson. "Population and Nutrition: A Case for Integration". Milbank Memorial Fund Quarterly Health and Society. Vol. 52. 1974. pp. 169-184.

2. Bean-porath, Yoram. "Economic Analysis of Fertility in Israel: Point and Counterpoint". Journal of Political Economy. Vol. 81, No. 2, pt. 2. March/April 1973. pp. 202-233.

3. Becker, Gary S. "An Economic Analysis of Fertility". In UniversitiesNational Bureau Committee for Economic Research. Demographic and Economic Change in Developed Countries. Princeton, N. J. : Princeton University Press. 1960. (Conference Series 11)

4. Becker, Gary. "A Theory of the Allocation of Time". Economic Journal. Vol. 75. September 1965 pp. 493-517.

5. Berg, Alan. The Nutrition Factor. Washington, D.C. : The Brooking Institute. 1973.

6. Bhattacharya, A. K. "Income Inequality and Fertility: A Comparative View”. Population Studies. Vol. 29. 1975. pp. 5-19.

7. Brown, Lester. The Social Impact of the Green Revolution. New York Carnegie Endowment for International Peace, January 1971. (Report No. 581)

8. Firebaugh, Glenn. "Cross-National Versus Historical Regression Analysis". Paper presented to American Sociological Association, San Francisco, September 1978.

9. Gardner, Bruce. "Economics of the size of North Carolina Rural Families" Journal of Political Economy. Vol. 81, No. 2, pt. 2. March/April 1973 pp. 99-122.

10. Grossman, Michael, The Demand for Health. New York: National Bureau of Economic Research. 1972.

11. Harman, Alvin J, Fertility and Economic Behaviour of Families in the Philip pines. Santa Monica: Rand Corporation. 1970. Rand Report No. RM6385 -AID.

12. Hassan, Shafick S. "Influence of Child Mortality on Fertility". Population Index. Vol. 32, No. 3. July 1966.

13. Heer, David. "Economic Development and the Fertility Transition". In D.V. Glass and Roger Revella (Eds.), Population and Social Change. New York: Crane. 1972.

14. Heller, Peter. "Interactions of Childhood Mortality and Fertility in W. Malaysia: 1947-1970". Ann Arbor: The University of Michigan, Center for Research on Economic Development. September 1976. (Discussion Paper No. 57; Mimeographed).
15. Kocher, James, Rural Development, Income Distribution, and Fertility Decline. New York: The Population Council. 1973.

16. Lancaster, Kelvin. "A New Approach to Consumer Theory". Journal of Political Economy. Vol. 74, April 1966. pp. 132-157.

17. Sahota, Gian S., and C. K. Sahota. "Green Revolution and Population Dynamics in India". (Unpublished manuscript prepared for the Smithsonian Institution, Washington, D.C.) 1975

18. Schultz, T. Paul. "Explanation of Birth Rate Changes Over Space and Time: A Study of Taiwan”. Journal of Political Economy. Vol. 81, No. 2, pt. 2, March/April 1973. pp. 238-274

19. Schultz, T. Paul. Fertility Determinants: A Theory, Evidence and Application to Policy Evaluation. Santa Monica: Rand Corporation. 1974

20. Schultz, T. Paul. "Fertility Patterns and Their Determinants in the Arab Middle East”. Santa Monica : Rand Corporation. 1973. (Rand Report No. RM-5978-FF)

21. Schultz, T. Paul. "Retrospective Evidence of a Decline of Fertility and Child Mortality in Bangladesh". Demography. Vol. 9, No. 3. August 1972. pp. 415-430.

22. Schultz, T. Paul. and Julie Davanzo. "Analysis of Demographic Change in East Pakistan: A Study of Retrospective Survey Data". Santa Monica: Rand Corporation. September 1970. (Rand Report No. R-564-AID)

23. Schultz, Theodore W. "The High Value of Human Time: Population Equilibrium". Journal of Political Economy. Vol. 82, March/April 1974 pp. $2-10$.

24. Todaro, Michael. Economic Development in the Third World. New York: Longman. 1977.

25. Weintraub, Robert. "The Birth Rate and Economic Development: An Empirical Study”. Econometrica. Vol. 40. 1962. pp. 812-817.

26. Williams, Anne D. "Determinants of Fertility in Developing Countries". In Michael C. Keeley (ed.). Population, Public Policy, and Economic Development. New York: Praeger Publishers. 1976. 